\title{
Proliferative retinopathy and proteinuria predict mortality rate in type 1 diabetic patients from Fyn County, Denmark
}

\author{
J. Grauslund • A. Green • A. K. Sjølie
}

Received: 13 November 2007 / Accepted: 21 January 2008 / Published online: 23 February 2008

(C) Springer-Verlag 2008

\begin{abstract}
Aims/hypothesis We evaluated the effect of diabetic retinopathy on 25 year survival rate among a population-based cohort of type 1 diabetic patients from Fyn County, Denmark. Methods In 1973 all diabetic patients from Fyn County, Denmark with onset before the age of 30 years as of 1 July 1973 were identified $(n=727)$. In 1981, only 627 patients were still alive and resident in Denmark. Of these, 573 (91\%) participated in a clinical baseline examination, in which diabetic retinopathy was graded and other markers of diabetes measured. Mortality rate was examined in a 25 year follow-up and related to the baseline examination.

Results Of the 573 patients examined at baseline in 1981 and 1982, 297 (51.8\%) were still alive in November 2006. Of the others, $256(44.7 \%)$ had died, three $(0.5 \%)$ had left Denmark and $17(3 \%)$ were of unknown status. Age- and sex-adjusted HRs of mortality rate were 1.01 (95\% CI $0.72-1.42)$ and $2.04(1.43-2.91)$ for patients with nonproliferative and proliferative retinopathy respectively at baseline compared with patients with no retinopathy. After adjusting for proteinuria, HR among patients with prolifera-
\end{abstract}

J. Grauslund $(\bowtie) \cdot$ A. K. Sjølie

Department of Ophthalmology, Odense University Hospital, Sdr. Boulevard 29,

DK-5000 Odense C, Denmark

e-mail: jakob.grauslund@ouh.regionsyddanmark.dk

\section{A. Green}

Department of Applied Research and Health Technology

Assessment (HTA), Odense University Hospital,

Odense, Denmark

\section{A. Green}

Department of Epidemiology, Institute of Public Health, University of Southern Denmark,

Odense, Denmark tive retinopathy lost statistical significance, but still remained 1.48 (95\% CI $0.98-2.23$ ). The 10 year survival rate of patients who had proliferative retinopathy as well as proteinuria at baseline was $22.2 \%$ and significantly lower $(p<0.001)$ than in patients with proteinuria only $(70.3 \%)$, proliferative retinopathy only $(79.0 \%)$ or neither $(86.6 \%)$. Conclusions/interpretation Proliferative retinopathy and proteinuria predict mortality rate in a population-based cohort of type 1 diabetic patients. In combination they act even more strongly. Non-proliferative diabetic retinopathy did not affect survival rate.

Keywords Diabetic retinopathy - Early onset .

Microvascular complications · Mortality .

Non-proliferative retinopathy Proliferative retinopathy .

Proteinuria $\cdot$ Retinopathy $\cdot$ Survival rate $\cdot$ Type 1 diabetes

\section{Introduction}

Type 1 diabetes is associated with higher all-cause mortality rates than those seen in the general population [1-5]. This excess mortality is mainly caused by the more frequent development of macrovascular diseases among these patients $[2,6-10]$.

The association between diabetic retinopathy and mortality rate in type 1 diabetic patients has been examined in several studies $[6,7,10-17]$, but only one study was population-based and presented long-term data [6].

In general the association between retinopathy and mortality rate is better investigated in type 1 diabetes because of the earlier onset and lower morbidity in this patient group than in patients with type 2 diabetes.

The aim of the current study was to evaluate the prognostic value of non-proliferative and proliferative 
retinopathy for survival rates in a 25 year follow-up among a population-based cohort of type 1 diabetic patients from Fyn County, Denmark. We also examined the role of additional risk factors such as sex, duration of diabetes, smoking, glycaemic control, blood pressure, BMI and proteinuria in the above associations.

\section{Methods}

Participants All diabetic patients resident in Fyn County, Denmark on 1 July 1973 whose onset of diabetes occurred before the age of 30 years as of 1 July $1973(n=727)$ were previously identified on the basis of insulin prescriptions $[18,19]$. At that time, the County of Fyn had approximately 450,000 inhabitants, thus being a demographically representative 9\% sample of the Danish population [18].

In 1981 all patients still alive and resident in Denmark $(n=627,86.2 \%)$ were invited to participate in a clinical follow-up investigation carried out between 1 June 1981 and 1 June 1982. Of these, $577(92.0 \%)$ participated in the baseline examination (Fig. 1). Data for four patients were subsequently lost, leaving baseline data available on 573 patients (321 men and 252 women). All participants gave written informed consent.

Baseline examination The clinical baseline examination was performed in 1981 and 1982 and included interview, ophthalmological examination, measurement of blood pressure, height and weight, and both blood and urine sampling [19].
Measurement of blood pressure was performed by means of an Erkameter sphygmomanometer (Morton Medical Ltd, London, UK) on one arm with the patient in sitting position after $10 \mathrm{~min}$ of rest. Measurements of the blood included $\mathrm{HbA}_{1 \mathrm{c}}$, done as total $\mathrm{HbA}_{1}$ with resin 70 (Bio-Rad, Hercules, CA, USA) at $20^{\circ} \mathrm{C}$ and $\mathrm{pH}$ 6.70. Urine protein was considered present, if greater than or equal to $0.5 \mathrm{~g} / 1$ protein was found in a spot urine sample. The patients were asked about their smoking habits. Both current and exsmokers were considered to be smokers for the upcoming models.

For both eyes the best corrected visual acuity was measured. Using tropicamide $1 \%$, both pupils were dilated and a slit lamp examination performed (Haag-Streit, Wedel, Germany). Ophthalmoscopy was performed and retinopathy was described and classified by a single trained observer. For further analysis, the worst eye determined the patient's level of retinopathy, which was classified as non-proliferative or proliferative retinopathy, if present. Non-proliferative retinopathy was defined as the presence of microaneurysms, haemorrhages, hard exudates, cotton wool spots, venous beading or intraretinal microvascular abnormalities in the retina. Proliferative retinopathy was defined as newly formed vessels in addition to the above. The presence of photocoagulation scars as panretinal treatment was also graded as proliferative retinopathy. Maculopathy was included in the category of non-proliferative retinopathy. Inclusion of patients with maculopathy in the proliferative group did not change the results of the study (data not shown).

At baseline, 143 participants (25.0\%) had no retinopathy, $291(50.8 \%)$ had non-proliferative retinopathy and 139
Fig. 1 Flow chart of type 1 diabetic patients from Fyn County, Denmark

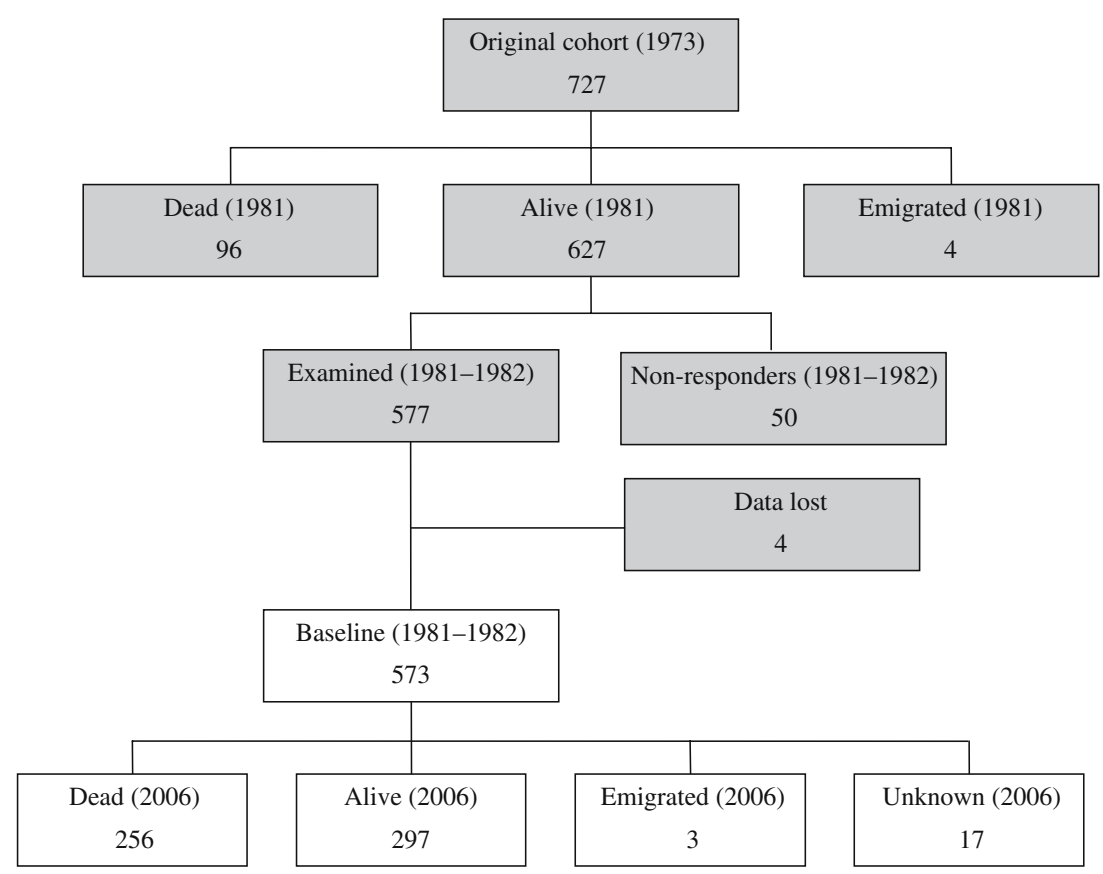


Table 1 Baseline characteristics (1981-1982) and 25 year survival rates according to level of retinopathy in type 1 diabetic patients from Fyn County, Denmark

\begin{tabular}{|c|c|c|c|c|}
\hline & No retinopathy & Non-proliferative retinopathy & Proliferative retinopathy & $p$ value \\
\hline$N$ & 143 & 291 & 139 & \\
\hline \multicolumn{5}{|l|}{ Baseline } \\
\hline Age (years) & $34 \pm 16$ & $39 \pm 12$ & $41 \pm 12$ & $<0.0001$ \\
\hline Sex $(\%$ male $)$ & 52 & 55 & 62 & 0.22 \\
\hline Duration diabetes (years) & $20 \pm 12$ & $22 \pm 10$ & $27 \pm 10$ & $<0.0001$ \\
\hline History of smoking (\%) & 55 & 68 & 74 & 0.002 \\
\hline $\mathrm{HbA}_{1 \mathrm{c}}(\%)$ & $8.73 \pm 0.67$ & $8.66 \pm 0.81$ & $8.29 \pm 1.15$ & $<0.0001$ \\
\hline $\mathrm{SBP}(\mathrm{mmHg})$ & $140 \pm 24$ & $148 \pm 22$ & $153 \pm 26$ & 0.0001 \\
\hline DBP (mmHg) & $91 \pm 13$ & $94 \pm 13$ & $95 \pm 14$ & 0.02 \\
\hline BMI $\left(\mathrm{kg} / \mathrm{m}^{2}\right)$ & $22.0 \pm 2.9$ & $22.6 \pm 2.7$ & $22.6 \pm 2.8$ & 0.10 \\
\hline Proteinuria (\%) & 5 & 8 & 30 & $<0.0001$ \\
\hline \multicolumn{5}{|l|}{ Follow-up } \\
\hline Survival rate $(\%)$ & 62.9 & 55.0 & 33.8 & $<0.0001$ \\
\hline
\end{tabular}

Data are means \pm SD or percentages. $p$ values tested with ANOVA for continuous variables and Pearson's $\chi^{2}$ test for categorical variables DBP, diastolic blood pressure; SBP, systolic blood pressure

(24.2\%) had proliferative retinopathy (Table 1$)$. On average, patients with proliferative retinopathy were older, had a longer duration of diabetes, were more likely to be current or former smokers, had a lower $\mathrm{HbA}_{1 \mathrm{c}}$, higher systolic and diastolic blood pressure, and were more likely to have proteinuria. There was no significant difference between the groups according to sex and BMI. Mean age at baseline examination was 38.3 years.

Follow-up In November 2006 data on mortality rates were collected from The Danish Civil Registration System. For those who had died, left Denmark or refused to provide data for scientific studies, we were informed of the date of death, emigration or refusal.

Statistical analysis Baseline characteristics are presented as percentage or mean $\pm \mathrm{SD}$ after ensuring normal distribution of the data. Statistical significance at the 0.05 level for any differences was tested with ANOVA for continuous variables and Pearson's $\chi^{2}$ test for categorical variables. The follow-up duration was calculated as the time between the baseline examination and date of death or date of loss to follow-up. Kaplan-Meier survival curves were plotted for all-cause mortality. Differences between curves were tested by the $\log$ rank test.

To evaluate the effect of diabetic retinopathy on survival, we used Cox's proportional hazard analyses to study the association between both non-proliferative and proliferative retinopathy at baseline and all-cause mortality compared with patients without retinopathy. The risks were calculated in a basic model, adjusting for age and sex only because of the known importance of these factors for survival rates. To determine which associations contributed to any elevated risk, we then made adjustments for different covariates in a oneby-one model. In the end, all previously added factors were included in a multivariate model in order to get an estimate of the independent predictive power of non-proliferative and proliferative retinopathy for all-cause mortality.

In the above model, we present our data as HRs with 95\% CIs. Confidence intervals that do not include 1.0 are regarded as statistically significant. All statistical analyses were performed in Stata Intercooled 9.2 (StataCorp, College Station, TX, USA).

\section{Results}

Of the 573 patients participating in the baseline examination, 297 (51.8\%) were still alive 25 years later, while 256 (44.7\%) had died, three $(0.5 \%)$ had emigrated and data were not available for 17 (3.0\%; Fig. 1). The breakdown of

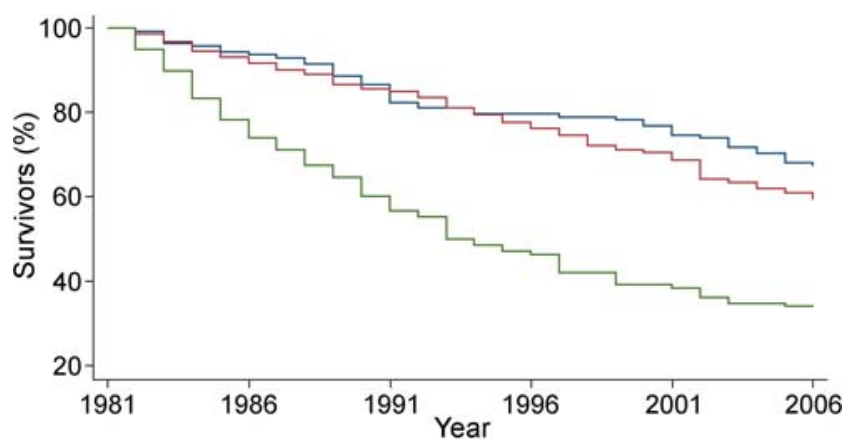

Fig. 2 All-cause mortality rate according to level of baseline retinopathy in type 1 diabetic patients from Fyn County, Denmark. Blue line, no retinopathy; brown line, non-proliferative retinopathy; green line, proliferative retinopathy 
Table 2 Age- and sex-adjusted HRs for all-cause mortality according to level of retinopathy compared with patients with no retinopathy in type 1 diabetic patients from Fyn County, Denmark

\begin{tabular}{|c|c|c|c|c|}
\hline & \multicolumn{4}{|c|}{ All-cause mortality rate } \\
\hline & \multicolumn{2}{|c|}{ Non-proliferative retinopathy } & \multicolumn{2}{|c|}{ Proliferative retinopathy } \\
\hline & HR $(95 \% \mathrm{CI})$ & $p$ value & $\mathrm{HR}(95 \% \mathrm{CI})$ & $p$ value \\
\hline Model 1: age, sex & $1.01(0.72-1.42)$ & 0.97 & $2.04(1.43-2.91)$ & $<0.001$ \\
\hline \multicolumn{5}{|l|}{ One-by-one adjustment } \\
\hline Model 1 and diabetes duration & $1.01(0.72-1.42)$ & 0.97 & $1.96(1.36-2.80)$ & 0.001 \\
\hline Model 1 and smoking & $1.01(0.73-1.43)$ & 0.92 & $2.01(1.41-2.87)$ & $<0.001$ \\
\hline Model 1 and $\mathrm{HbA}_{1 \mathrm{c}}$ & $1.07(0.76-1.51)$ & 0.71 & $2.16(1.51-3.09)$ & $<0.001$ \\
\hline Model 1 and SBP & $1.00(0.71-1.41)$ & 0.99 & $2.02(1.42-2.89)$ & $<0.001$ \\
\hline Model 1 and DBP & $1.01(0.71-1.41)$ & 0.98 & $2.03(1.42-2.90)$ & $<0.001$ \\
\hline Model 1 and BMI & $1.04(0.73-1.47)$ & 0.85 & $2.06(1.42-2.97)$ & $<0.001$ \\
\hline Model 1 and proteinuria & $0.98(0.68-1.41)$ & 0.90 & $1.49(0.99-2.24)$ & 0.054 \\
\hline \multicolumn{5}{|l|}{ Multivariate model } \\
\hline Model 1 plus ${ }^{\text {a }}$ & $0.98(0.68-1.42)$ & 0.91 & $1.48(0.98-2.23)$ & 0.060 \\
\hline
\end{tabular}

HR $(95 \% \mathrm{CI})$ for all-cause mortality rate analysed by Cox's proportional hazards analyses

DBP, diastolic blood pressure; SBP, systolic blood pressure

${ }^{a}$ Model 1 plus diabetes duration, smoking, $\mathrm{HbA}_{1 \mathrm{c}}$, SBP, DBP, BMI and proteinuria

deaths was: 147 men (45.8\%) and 109 women (43.3\%). There was no difference in mortality rates between the two sexes $(p=0.52)$.

According to level of retinopathy at baseline, 25 year survival rate was $62.9 \%$ for patients with no retinopathy, $55.0 \%$ for patients with non-proliferative retinopathy and $33.8 \%$ for patients with proliferative retinopathy, respectively (Fig. 2).

Age- and sex-adjusted HRs for non-proliferative retinopathy and proliferative retinopathy were 1.01 (95\% CI 0.72 1.42) and 2.04 (95\% CI 1.43-2.91), respectively (Table 2), compared with patients without retinopathy. HR for all-cause mortality among patients with proliferative retinopathy was 1.49 (95\% CI 0.99-2.24) when adjusted for proteinuria. Adjusting for other covariates in a one-by-one adjustment had only a small impact on all-cause mortality rate. In a multivariate model, HR for proliferative retinopathy still remained 1.48 (95\% CI 0.98-2.23), although not statistically significant. The elevated HR for all-cause mortality among patients with proliferative retinopathy is thus explained partly, but not entirely, by other risk factors, of which proteinuria seems to be the most important.

In order to evaluate the combined and separate effects of proliferative retinopathy and proteinuria on survival, patients were divided into four groups according to the presence and absence of proliferative retinopathy and proteinuria at baseline (Fig. 3). The 25 year survival rate was $66.4 \%$ for patients with neither proliferative retinopathy nor proteinuria, $48.2 \%$ for patients with proliferative retinopathy only, $33.3 \%$ for patients with proteinuria only and $16.7 \%$ for patients who had both proliferative retinop- athy and proteinuria at baseline $(p<0.001)$. Mean ages at baseline for the four groups were 36.7, 40.9, 38.6 and 41.1 years, respectively.

Interestingly, the 10 year survival rate for patients with proliferative retinopathy and proteinuria at baseline was $22.2 \%$ versus $86.8 \%$ in the group of patients with neither proliferative retinopathy nor proteinuria, $79.0 \%$ in those with proliferative retinopathy only and $70.4 \%$ in the group with proteinuria only.

\section{Discussion}

In the current 25 year follow-up study, we found a significantly lower survival rate among type 1 diabetic patients

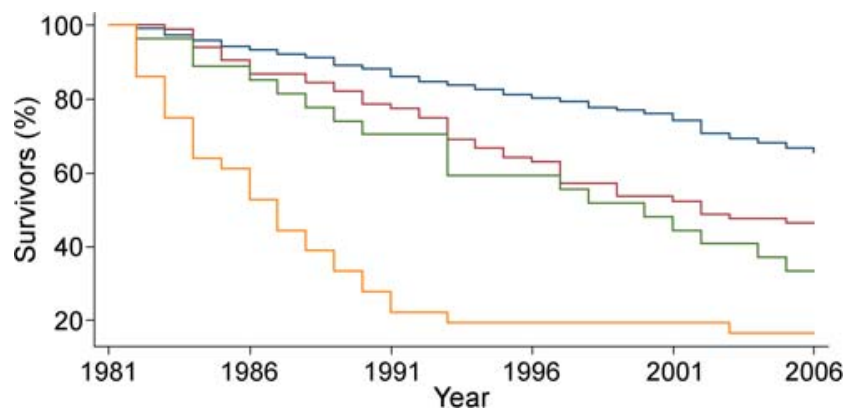

Fig. 3 All-cause mortality rate according to level of baseline retinopathy and proteinuria in type 1 diabetic patients from Fyn County, Denmark. Blue line, no proliferative retinopathy, no proteinuria; brown line, proliferative retinopathy, no proteinuria; green line, no proliferative retinopathy, proteinuria; orange line, proliferative retinopathy, proteinuria 
who had proliferative retinopathy compared with patients who had no retinopathy or non-proliferative retinopathy, respectively. Adjusted for age and sex, the HR for all-cause mortality was 2.04 (95\% CI 1.43-2.91) for proliferative retinopathy and 1.01 (95\% CI $0.72-1.42)$ for non-proliferative retinopathy, respectively. After adjusting for other risk factors, the HR for proliferative retinopathy was no longer statistically significantly increased, but remained at 1.48 (95\% CI $0.98-2.23)$. We found that proliferative retinopathy and proteinuria were the only important markers of mortality rate. The 10 year survival rate was only $22.2 \%$ for patients who had both proliferative retinopathy and proteinuria at baseline. This was significantly lower than for patients who had only proliferative retinopathy, only proteinuria or neither.

Our study has several limitations. Baseline data were collected in 1981 and 1982. The methods available then would not live up to the standards of today. Ophthalmoscopy was used to grade retinopathy, as fundus photography was not available. Retinopathy was found in $75.0 \%$ (430 of 573 ) patients after a mean duration of 23 years. Other studies have shown the prevalence of retinopathy after 20 years to be more than $80 \%$ [20-22]. The explanation of this could be that retinopathy was misclassified in some of our patients due to the lower sensitivity of ophthalmoscopy compared with fundus photography [23]. Moreover, differentiation between different degrees of non-proliferative retinopathy was not performed. Subclassification of nonproliferative retinopathy might have given valuable additional information. We used a single spot of urine to evaluate whether proteinuria was present. The standard today is to use multiple collections due to the substantial intra-individual variability in urinary albumin excretion rate [24]. Furthermore, in our study, analysis for microalbuminuria was not available at the time of the baseline examination.

Population-based long-term data on survival rates among type 1 diabetic patients according to level of retinopathy at baseline has only been presented in two earlier studies. In a 16 year follow-up of the Wisconsin Epidemiologic Study of Diabetic Retinopathy, Klein et al. found severity of retinopathy at baseline to be associated with all-cause and ischaemic heart disease mortality rates among 996 younger onset patients [6]. Adjusted for age and sex, all-cause HR in that study was 5.53 (95\% CI 3.06-9.99) for patients with proliferative retinopathy at baseline. After adjusting for other risk factors this association lost significance (HR $1.28,95 \%$ CI $0.62-2.62$ ). It was stated that the greatest impact on reducing the HRs came when blood pressure or gross proteinuria was added as adjusting risk factor to the model. In an 8 year follow-up in the EURODIAB Prospective Complications Study, van Hecke et al. [11] examined mortality according to level of retinopathy at baseline among 2,237 European type 1 diabetic patients. The age- and sex-adjusted HR of all-cause mortality was 4.16 (95\% CI 1.96-8.84) in patients with proliferative retinopathy. In a multivariate model this was no longer statistically significant, albeit still increased (HR 2.06, 95\% CI 0.63-6.73). Although many patients were included, the study was biased in that it was not population-based. To our knowledge, the combined effect of retinopathy and renal dysfunction on mortality rate has only been established in type 2 diabetes $[25,26]$.

In conclusion, we found both proliferative retinopathy and proteinuria to be independent markers of mortality rates among type 1 diabetic patients. In combination they strongly predicted mortality rate. For patients with both complications, the 10 year survival rate was only $22.2 \%$.

Acknowledgements This work was supported by grants from Velux Foundation, the Danish Eye Health Society, Sehested Hansen's Foundation, Danish Diabetes Association and the A. P. Møller Foundation for the Advancement of Medical Science. For statistical support we would like to thank W. Vach, (Department of Statistics, University of Southern Denmark, Odense, Denmark).

Duality of interest The authors declare that there is no duality of interest associated with this manuscript.

\section{References}

1. Soedamah-Muthu SS, Fuller JH, Mulnier HE, Raleigh VS, Lawrenson RA, Colhoun HM (2006) All-cause mortality rates in patients with type 1 diabetes mellitus compared with a nondiabetic population from the UK general practice research database, 1992-1999. Diabetologia 49:660-666

2. Morrish NJ, Wang SL, Stevens LK, Fuller JH, Keen H (2001) Mortality and causes of death in the WHO Multinational Study of Vascular Disease in Diabetes. Diabetologia 44(Suppl 2):S14-S21

3. Asao K, Sarti C, Forsen T et al (2003) Long-term mortality in nationwide cohorts of childhood-onset type 1 diabetes in Japan and Finland. Diabetes Care 26:2037-2042

4. Laing SP, Swerdlow AJ, Slater SD et al (1999) The British Diabetic Association Cohort Study, I: all-cause mortality in patients with insulin-treated diabetes mellitus. Diabet Med 16:459-465

5. Dorman JS, LaPorte RE, Kuller LH et al (1984) The Pittsburgh insulin-dependent diabetes mellitus (IDDM) morbidity and mortality study. Mortality results. Diabetes 33:271-276

6. Klein R, Klein BE, Moss SE, Cruickshanks KJ (1999) Association of ocular disease and mortality in a diabetic population. Arch Ophthalmol 117:1487-1495

7. Rajala U, Pajunpaa H, Koskela P, Keinanen-Kiukaanniemi S (2000) High cardiovascular disease mortality in subjects with visual impairment caused by diabetic retinopathy. Diabetes Care 23:957-961

8. Wong JS, Pearson DW, Murchison LE, Williams MJ, Narayan V (1991) Mortality in diabetes mellitus: experience of a geographically defined population. Diabet Med 8:135-139

9. Waugh NR, Dallas JH, Jung RT, Newton RW (1989) Mortality in a cohort of diabetic patients. Causes and relative risks. Diabetologia 32:103-104 
10. Henricsson M, Nilsson A, Heijl A, Janzon L, Groop L (1997) Mortality in diabetic patients participating in an ophthalmological control and screening programme. Diabet Med 14:576-583

11. van Hecke MV, Dekker JM, Stehouwer CD et al (2005) Diabetic retinopathy is associated with mortality and cardiovascular disease incidence: the EURODIAB prospective complications study. Diabetes Care 28:1383-1389

12. Klein BE, Klein R, McBride PE et al (2004) Cardiovascular disease, mortality, and retinal microvascular characteristics in type 1 diabetes: Wisconsin epidemiologic study of diabetic retinopathy. Arch Intern Med 164:1917-1924

13. Klein R, Moss SE, Klein BE, DeMets DL (1989) Relation of ocular and systemic factors to survival in diabetes. Arch Intern Med 149:266-272

14. Cusick M, Meleth AD, Agron E et al (2005) Associations of mortality and diabetes complications in patients with type 1 and type 2 diabetes: early treatment diabetic retinopathy study report no. 27. Diabetes Care 28:617-625

15. Walters DP, Gatling W, Houston AC, Mullee MA, Julious SA, Hill RD (1994) Mortality in diabetic subjects: an eleven-year follow-up of a community-based population. Diabet Med 11:968-973

16. Davis MD, Hiller R, Magli YL et al (1979) Prognosis for life in patients with diabetes: relation to severity of retinopathy. Trans Am Ophthalmol Soc 77:144-170

17. Roy M, Rendas-Baum R, Skurnick J (2006) Mortality in AfricanAmericans with type 1 diabetes: The New Jersey 725. Diabet Med 23:698-706

18. Green A, Hauge M, Holm NV, Rasch LL (1981) Epidemiological studies of diabetes mellitus in Denmark. II. A prevalence study based on insulin prescriptions. Diabetologia 20:468-470
19. Sjolie AK (1985) Ocular complications in insulin treated diabetes mellitus. An epidemiological study. Acta Ophthalmol Suppl 172:1-77

20. Klein R, Klein BE, Moss SE, Davis MD, DeMets DL (1984) The Wisconsin epidemiologic study of diabetic retinopathy. II. Prevalence and risk of diabetic retinopathy when age at diagnosis is less than 30 years. Arch Ophthalmol 102:520-526

21. Orchard TJ, Dorman JS, Maser RE et al (1990) Prevalence of complications in IDDM by sex and duration. Pittsburgh Epidemiology of Diabetes Complications Study II. Diabetes 39:11161124

22. No authors listed (1994) Microvascular and acute complications in IDDM patients: the EURODIAB IDDM Complications Study. Diabetologia 37:278-285

23. Lin DY, Blumenkranz MS, Brothers RJ, Grosvenor DM (2002) The sensitivity and specificity of single-field nonmydriatic monochromatic digital fundus photography with remote image interpretation for diabetic retinopathy screening: a comparison with ophthalmoscopy and standardized mydriatic color photography. Am J Ophthalmol 134:204-213

24. Klein R, Klein BE, Moss SE (1991) The incidence of gross proteinuria in people with insulin-dependent diabetes mellitus. Arch Intern Med 151:1344-1348

25. Ono T, Kobayashi J, Sasako Y et al (2002) The impact of diabetic retinopathy on long-term outcome following coronary artery bypass graft surgery. J Am Coll Cardiol 40:428-436

26. Tong PC, Kong AP, So WY et al (2007) Interactive effect of retinopathy and macroalbuminuria on all-cause mortality, cardiovascular and renal end points in Chinese patients with type 2 diabetes mellitus. Diabet Med 24:741-746 